Article

\title{
Carminic Acid Linked to Silica Nanoparticles as Pigment/Antioxidant Bifunctional Excipient for Pharmaceutical Emulsions
}

\author{
Francisco Arriagada ${ }^{1}\left(\mathbb{0}\right.$, Catalina Ugarte ${ }^{2}$, Germán Günther ${ }^{2}{ }^{(0}$, María Angélica Larraín ${ }^{2}{ }^{(1)}$, \\ Víctor Guarnizo-Herrero ${ }^{3}$, Santi Nonell ${ }^{4}\left(\mathbb{D}\right.$ and Javier Morales ${ }^{2, *}$ \\ 1 Instituto de Farmacia, Facultad de Ciencias, Universidad Austral de Chile, 5110033 Valdivia, Chile; \\ francisco.arriagada@uach.cl \\ 2 Facultad de Ciencias Químicas y Farmacéuticas, Universidad de Chile, 8380494 Santiago, Chile; \\ caugarte35@hotmail.com (C.U.); ggunther@ciq.uchile.cl (G.G.); mlarrain@uchile.cl (M.A.L.) \\ 3 Facultad de Farmacia, Universidad Complutense de Madrid, 28040 Madrid, Spain; victor08@ucm.es \\ 4 Institut Químic de Sarrià (IQS), Universidad Ramon Llull. Via Augusta 390, 08017 Barcelona, Spain; \\ santi.nonell@iqs.url.edu \\ * Correspondence: javiermv@ciq.uchile.cl
}

Received: 7 February 2020; Accepted: 8 April 2020; Published: 19 April 2020

\begin{abstract}
The incorporation of pigments and natural polyphenols into inorganic matrices, resulting in a hybrid material that improves the resistance and chemical stability of the pigments and the antioxidant capacity of the materials, has been of great interest to the pharmaceutical, chemical and food industries. The aim of this work was to prepare and characterize a bifunctional pigment-antioxidant nanomaterial-based carminic acid-decorated solid core-mesoporous shell silica nanoparticles, evaluating its properties as a pigment, its antioxidant capacity and its properties as a chemical stabilizer of emulsions. The chemical stability of oil-in-water $(\mathrm{O} / \mathrm{W})$ Pickering emulsions was evaluated determining the stability of vitamin E solubilized in the oil phase. Carminic acid was attached through the action of coupling ethylcarbodiimide hydrochloride (EDC)/N-hydroxysuccinimide (NHS) agents, and the resulting spherical and homogeneous nanoparticles showed a diameter close to $175 \mathrm{~nm}$. A notorious change of emulsion color was observed by the addition of the nanomaterial. Emulsions showed an attractive pink color, and when the $\mathrm{pH}$ was adjusted to $\mathrm{pH} 3$ and $\mathrm{pH}$ 9, a change in color was observed, analogous to carminic acid in solution. The nanomaterial incorporation also improved chemical stability, decreasing vitamin E consumption to $9.26 \%$ of the initial value, demonstrating an important antioxidant effect of the developed nanomaterial.
\end{abstract}

Keywords: carminic acid; emulsion; antioxidant; silica nanoparticles; nanoexcipients

\section{Introduction}

In pharmaceutical, cosmetic and food products, as emulsions, color is a crucial factor defining quality and consumer perception. Emulsion coloration depends on several droplet properties (size, concentration, aggregation and relative refractive index), and when present, also on pigment absorption efficiency (mainly determined by its absorption spectra and concentration). Thus, the emulsion's visual appearance results from the combination of scattered and absorbed light [1]. Carminic acid (CA) is a common natural hydroxyanthraquinone pigment, used for coloring pharmaceutical, cosmetic or food formulations in a wide range of red shades [2], dependent on $\mathrm{pH}$. In addition, it has excellent heat and light stability [3,4]. Moreover, besides these properties, several studies have reported CA to act as antioxidant against free radicals and reactive oxygen species (ROS), such as singlet oxygen [5-8]. 
Emulsions are thermodynamically unstable systems, which, by the addition of surfactants and/or solid particles or a mixture of surfactant with other amphiphilic polymers, can be kinetically stabilized [9-12]. When solid particles are used to stabilize an emulsion, it is known as a Pickering emulsion $[13,14]$. The "emulsifier-free" character of Pickering emulsions makes them attractive in applications where surfactants have detrimental effects on both human health and environment [15-18]. The enhanced stability of Pickering emulsions, with respect to classical emulsions stabilized by emulsifiers, is a supplementary advantage. The coating of droplets by solid particles constitutes a physical rigid barrier acting against coalescence; therefore, emulsions are efficiently stabilized $[19,20]$.

Several materials have been used to prepare Pickering emulsions [21-25]; among them, silica is the most popular, because its surface is easily modified, either by chemical reaction or by physical adsorption of various compounds such as salts, low molecular weight surfactants, polymers and pigments and natural polyphenols, among others [25-32]. In particular, different types of silica materials (MCM-41, SBA-16, etc.) have been used for various pharmaceutical purposes, such as drug delivery systems (DDS) [33-35], to improve the dissolution rate of drugs [36], to limit cutaneous penetration of organic UV filters [37] or even as pigment (or drug) removers from water [38]. These porous materials present a high specific surface area that allows a large amount of drug to be incorporated; nonetheless, several authors have reported modifications to the synthesis process, in order to obtain improvements in the properties of silica nanoparticles. For example, the synthesis of core-shell silica materials (dense core and mesoporous shell) allows for a suitable density of particles for the adsorption at the interface of an oil-in-water $(\mathrm{O} / \mathrm{W})$ emulsion and, at the same time, to have a high surface area to incorporate different molecules of pharmaceutical interest. Among these different biomolecules, various studies have shown that adsorption and linkage of natural polyphenols on the silica surface maintains the antioxidant capacity, improving the stability of nanomaterial [39-42]. Norton et al. showed that silica particles could increase the oxidative stability of $\mathrm{O} / \mathrm{W}$ emulsions by acting as a physical barrier between pro-oxidants present in a continuous phase and hydroperoxides located at droplet interface [17,43].

The incorporation of a pigment to inorganic matrices to obtain a hybrid material that improves the resistance and chemical stability of the pigments has been widely studied in several fields of application and different production methodologies [44-48].

The immobilization of a pigment onto silica nanoparticles is an attractive approach to obtain hybrid materials that take advantage of the carminic acid color and antioxidant properties, as well as the silica nanoparticle stable matrix. In particular, its incorporation into emulsions in the field of the pharmaceutical industry is of great interest. In skin applications and dermatological formulations, the size of nanoparticles is a crucial factor [49]. Some authors suggest that these kinds of nanoparticles are able to penetrate skin. For example, Rancan et al. demonstrated that $42 \mathrm{~nm}$ silica nanoparticles (SNPs), applied on human skin explants, with a partially disrupted stratum corneum, were localized in hair follicles and can be internalized by epidermal and dendritic cells. Other researchers have obtained similar conclusions $[50,51]$. On the other hand, some authors reported that in vivo, skin penetration of $55 \mathrm{~nm}$ diameter ( $111 \mathrm{~nm}$ hydrodynamic diameter in ultrapure water) functionalized silica nanoparticles was not observed after one or five consecutive days of topical application [52]. In addition, it is relatively well accepted that bigger size nanoparticles (75 $\mathrm{nm}$ and larger) cannot penetrate the skin [53]. In this work, we prepared nanoparticles of about $200 \mathrm{~nm}$, which cannot penetrate the skin. The silica nanoparticles with carminic acid covalently linked could be a safe, efficient and novel bifunctional pigment-antioxidant nano-excipient to stabilize $\mathrm{O} / \mathrm{W}$ pharmaceutical emulsions.

The aim of this work was to prepare and characterize carminic acid decorated solid core-mesoporous shell silica nanoparticles, evaluating their properties as a pigment, their antioxidant capacity and the chemical stabilizing properties of Pickering emulsions. Unlike physical adsorption, the chemical immobilization of polyphenols on the surface of solid core-mesoporous shell silica nanoparticles prevents their release by desorption and also prevents the formation of dimers and other aggregates that usually decrease their antioxidant capacity. The chemical stability of $\mathrm{O} / \mathrm{W}$ Pickering emulsions was evaluated determining the stability of vitamin E ( $\alpha$-tocopherol) solubilized in the oil 
phase. This bioactive compound was selected as a model hydrophobic drug, because of its high susceptibility to oxidation.

\section{Materials and Methods}

\subsection{Materials}

Carminic acid (CA, $\geq 92 \%)$ was purchased from Merck (Darmstadt, Germany). N-hydroxysuccinimide (NHS, 98\%), N-(3-dimethylaminopropyl)- $N$ '-ethylcarbodiimide hydrochloride (EDC, $\geq 98 \%$ ), tetraethyl orthosilicate (TEOS, 98\%), (3-aminopropyl)triethoxysilane (APTES, $\geq 98 \%$ ), hexadecyltrimethylammonium bromide $(\mathrm{CTAB}, \geq 98 \%)$, deuterium oxide $\left(\mathrm{D}_{2} \mathrm{O}, 99.990\right.$ atom \% $\left.\mathrm{D}\right)$, alfa tocopherol (Vitamin E, $96 \mathrm{wt}$ \%), $3 \AA$ molecular sieves, and phenalenone were purchased from Sigma-Aldrich (St. Louis, MO, USA). Surfactants Tween $60^{\circledR}$ and Span $60^{\circledR}$ were obtained from Sigma-Aldrich, while glycerin, castor oil, mineral oil and cetyl alcohol were purchased from CRODA International PLC (CRODA Chile, Santiago, Chile). Ethanol (HPLC grade), acetonitrile (HPLC grade), methanol (HPLC grade), acetone (HPLC grade) and triethylamine (TEA, $\geq 99 \%$ ) were obtained from Merck. Ammonium hydroxide $\left(\mathrm{NH}_{4} \mathrm{OH}\right.$, acs reagent $\left.28 \%-30 \%\right)$ was purchased from J.T. Baker (Phillipsburg, NJ, USA). Deionized water (Milli-Q, $18.2 \mathrm{M} \Omega . \mathrm{cm}$ ) was used in all experiments performed. All materials were used as received.

\subsection{Preparation of Silica Nanoparticles (SNPS)}

SNPs were obtained by a modified Stöber method following slight modifications [54-56]. Briefly, for a typical synthesis of SNPs around $100 \mathrm{~nm}$ in diameter, ethanol $(44 \mathrm{~mL})$, deionized water $(3 \mathrm{~mL})$ and ammonium hydroxide $(1.3 \mathrm{~mL})$ were added to a round-bottomed flask and stirred for $10 \mathrm{~min}$. Later, TEOS $(1.73 \mathrm{~mL})$ was added to the mixture and allowed to react for $3 \mathrm{~h}$ under stirring $(850 \mathrm{rpm})$ at room temperature. The nanoparticles (SNPs) were obtained by centrifugation $(15,000 \times g)$ and washed with water and ethanol several times. Finally, the product was dried and stored until further use.

\subsection{Preparation of Solid Core-Mesoporous Shell Silica Nanoparticles (CSSNPs)}

First, $2.3 \mathrm{~g}$ of CTAB and $15 \mu \mathrm{L}$ of TEA were mixed in water, then $300 \mathrm{mg}$ of SNPs, were added to the solution and stirred at room temperature for $30 \mathrm{~min}$. The suspension was heated up to $80^{\circ} \mathrm{C}$ and $150 \mu \mathrm{L}$ of TEOS were added dropwise and stirred for $1 \mathrm{~h}$ at $80^{\circ} \mathrm{C}$. Then, the product was washed once with water, re-suspended in a $1 \mathrm{wt} \%$ solution of $\mathrm{NaCl}$ and stirred overnight to remove CTAB. The CTAB extraction process was carried out several times to ensure its complete removal. Finally, the product was obtained by centrifugation, dried and designated as CSSNPs.

\subsection{Preparation of Amino-Functionalized Solid Core-Mesoporous Shell Silica Nanoparticles (ACSSNPs)}

$300 \mathrm{mg}$ of the above CSSNPs were suspended in $50 \mathrm{~mL}$ of ethanol at $40{ }^{\circ} \mathrm{C}$ and $250 \mu \mathrm{L}$ of APTES were added. The mixture was stirred for $12 \mathrm{~h}$ at $40{ }^{\circ} \mathrm{C}$, and the modified nanoparticles were then centrifuged and washed with ethanol. The resulting nanoparticles (ACSSNPs) were dried and stored until further use.

\subsection{Conjugation of Carminic Acid to Amino-Functionalized Core-Shell Silica Nanoparticles by EDC/NHS Coupling Chemistry (ACSSNPs-CA)}

Grafting of carminic acid (CA) to ACSSNPs was achieved by coupling its -COOH group to the $-\mathrm{NH}_{2}$ group of ACSSNPs using the EDC/NHS coupling agents [57]. In a typical synthesis, $6.0 \mathrm{mg}$ of $\mathrm{CA}, 4.6 \mathrm{mg}$ of EDC and $5.6 \mathrm{mg}$ of NHS were dissolved in water, and the mixture was sonicated for $15 \mathrm{~min}$. After this, the mixture was added dropwise to a suspension of $100 \mathrm{mg}$ of ACSSNPs, and the reaction was allowed to proceed under stirring for $6 \mathrm{~h}$ at room temperature [42]. The product was collected by centrifugation and washed three times with ethanol to remove by-products and unreacted reagents. The nanoparticles (ACSSNPs-CA) were dried and stored until further use. 


\subsection{Characterization of Nanoparticles}

The hydrodynamic diameter of nanoparticles suspended in ethanol was measured by dynamic light scattering (DLS) at $25^{\circ} \mathrm{C}$, using a Malvern Zetasizer Nano ZS90 (Malvern, UK) with a detection angle of $173^{\circ}$ and equilibration time of $120 \mathrm{~s}$. Each measurement was performed three times. Zeta potentials were obtained using the same equipment at $25^{\circ} \mathrm{C}$ with the nanoparticles suspended in deionized water. Morphological analysis using STEM was taken on an FEI $^{\mathrm{TM}}$ inspect F50 model microscope, with an accelerating voltage of $10.00 \mathrm{kV}$. Fourier transform infrared (FT-IR) spectra were obtained using an Interspec 200-X FT-IR spectrometer with $4 \mathrm{~cm}^{-1}$ resolution, between in 4000 and $400 \mathrm{~cm}^{-1}$, averaging 16 scans. The thermogravimetric analysis (TGA) were performed using a Netzsch TG 209 F1, under air flow of $20 \mathrm{~mL} \mathrm{~min}^{-1}$ with a heating rate of $10{ }^{\circ} \mathrm{C} \mathrm{min}^{-1}$ in the range of $20-800{ }^{\circ} \mathrm{C}$.

\subsection{Determination of Carminic Acid Amount Covalently Linked to ACSSNPS}

Determination of CA grafting onto nanoparticles was also quantified by a previously validated HPLC indirect method. Chromatographic analysis was performed on a Prominence HPLC system (Shimadzu, Tokyo, Japan) using a Chromolith Performance RP-18 monolithic (4.6×100 mm) from Merck. Isocratic elution was performed using a mobile phase consisting of methanol: $0.1 \%$ trifluoroacetic acid solution $(30: 70 \mathrm{v} / \mathrm{v})$, at a flow rate of $1.0 \mathrm{~mL} / \mathrm{min}$. The sample injection volume was $50 \mu \mathrm{L}$, the run time was $14 \mathrm{~min}$ and the retention time was $9.0 \mathrm{~min}$. PDA detector was set at $499 \mathrm{~nm}$. Data were obtained from triplicate analysis.

\subsection{Antioxidant Assay: Singlet Oxygen Quenching}

Direct detection of singlet oxygen $\left({ }^{1} \mathrm{O}_{2}\right)$ near-infrared phosphorescence at $1275 \mathrm{~nm}$ was performed using a customized PicoQuant Fluotime 200 lifetime system [58]. A diode-pumped pulsed Nd:YAG laser (CryLas, FTSS355-Q, Berlin, Germany) working at $1 \mathrm{kHz}$ repetition rate at $532 \mathrm{~nm}$ was used for excitation. The time-resolved ${ }^{1} \mathrm{O}_{2}$ emission data were fitted to the Equation (1) [59] using GraphPad Prism 5 software:

$$
\mathrm{S}(\mathrm{t})=\mathrm{S}_{0} \frac{\tau_{\Delta}}{\tau_{\Delta}-\tau_{\mathrm{T}}}\left(\mathrm{e}^{-\frac{\mathrm{t}}{\tau_{\Delta}}}-\mathrm{e}^{-\frac{\mathrm{t}}{\tau_{\mathrm{T}}}}\right)
$$

where $S(t)$ is the ${ }^{1} \mathrm{O}_{2}$ signal intensity at time $t, S_{0}$ is an empirical parameter proportional to singlet oxygen quantum yield, $\tau_{\Delta}$ is the ${ }^{1} \mathrm{O}_{2}$ lifetime and $\tau_{\mathrm{T}}$ is the triplet-state lifetime [59]. The total quenching rate constant $\left(k_{\mathrm{T}}\right)$ for the deactivation of ${ }^{1} \mathrm{O}_{2}$ by ACSSNPs-CA or free CA in acetone and deuterium oxide $\left(\mathrm{D}_{2} \mathrm{O}\right)$ was obtained by measuring the first-order luminescence decay of singlet oxygen in the presence and absence of quencher and using phenalenone as sensitizer. A control using CA-free nanoparticles under the same conditions above mentioned was measured. The $k_{\mathrm{T}}$ values were calculated from the slope of the Stern-Volmer plots, according to Equation (2):

$$
\tau^{-1}=\tau_{0}^{-1}+\mathrm{k}_{\mathrm{q}}[\mathrm{Q}]
$$

where $\tau^{-1}$ and $\tau_{0}^{-1}$ are the singlet oxygen lifetime in presence and absence of quencher [Q], respectively [59].

\subsection{Color Measurement}

Color space values of ACSSNPs-CA dispersed in hydroxyethylcellulose solutions were determined using a Hunterlab (10D65) colorimeter (Reston, VA, USA), where color has a unique location, as defined by its Cartesian coordinates with respect to $a^{*}$ (red-green axis), $b^{*}$ (yellow-blue axis) and $L^{*}$ (lightness axis) for the brightness (CIE system) [60]. In addition, the color difference $(\Delta \mathrm{E})$ was calculated using coordinate geometry, considering that the human eye can perceive a color change corresponding to a value of $\Delta \mathrm{E}>1.5[61]$. 


\subsection{Stability of Nanoparticles under Oxidative Conditions}

Samples of $150 \mathrm{mg}$ of ACSSNPs-CA dispersed in $7 \mathrm{~mL}$ of water were mixed with $3 \mathrm{~mL}$ of $30 \%$ $\mathrm{H}_{2} \mathrm{O}_{2}$ solution to obtain a final concentration of $15 \mathrm{mg} \mathrm{mL}^{-1}$. The mixture was homogenized in a vortex mixer. The samples were stored in vials, during $1,2,3,4$ and 5 days at $40 \pm 2{ }^{\circ} \mathrm{C}$ and $70 \%$ $\mathrm{RH} \pm 5 \%$. After this, each sample was collected by centrifugation $(15,000 \times g)$, washed with water and ethanol several times, and finally dried and stored until further use.

\subsection{UV-Visible Spectroscopy Measurements}

A single-beam UV-visible Agilent 8453 spectrophotometer (Agilent Technologies, Shanghai, China) equipped with $1 \mathrm{~cm}$ quartz cells was used to characterize the UV-visible absorption properties of CA solutions and ACSSNPs-CA dispersions in ethanol, deionized water, glycerin solutions and mineral oil and acetone using the same concentration. All absorption spectra were analyzed using UV-visible ChemStation Software of Agilent Technologies. The UV-visible absorption spectra for ACSSNPs-CA were performed for each suspension using ACSSNPs as blank, in order to subtract the scattering generated by the nanoparticles.

\subsection{Incorporation of Nanoparticles in Emulsions}

\subsubsection{Preparation of Emulsions}

A total of $100 \mathrm{~g}$ of emulsion was prepared by mixing the aqueous phase $(4.0 \mathrm{~g}$ glycerin and $78 \mathrm{~g}$ water) and the oil phase ( $7 \mathrm{~g}$ mineral oil, 1.5 cetyl alcohol, $3.0 \mathrm{~g}$ castor oil and $0.5 \mathrm{~g}$ vitamin $\mathrm{E}$ under vigorous stirring (1000 rpm) using an IKA Eurostar 20 Digital overhead stirrer during $5 \mathrm{~min}$ at $80^{\circ} \mathrm{C}$ [62]. The surfactants (2.4 g Tween 60 and $1.1 \mathrm{~g}$ Span 60 ) were added in the oil phase. The preparation was cooled to room temperature under slow stirring. Water lost by evaporation was replenished. Three formulations were prepared, one incorporating ACSSNPs-CA, a second one with ACSSNPs, and a final emulsion without nanoparticles. To this aim, the nanoparticle powder (ACSSNPs-CA or ACSSNPs) was dispersed in glycerin and sonicated for $15 \mathrm{~min}$. Then, $300 \mu \mathrm{L}$ of water were added to the mixture. Finally, the emulsion was added in small quantities under vigorous stirring. Final concentration of nanoparticles in the emulsions were $0.1 \mathrm{wt} \%, 0.5 \mathrm{wt} \%$ and $1 \mathrm{wt} \%$. All emulsions contain vitamin $\mathrm{E}$ $0.5 \mathrm{wt} \%$, to simulate the composition of existing commercial products. The nanoparticle-free emulsions were designated as E- 0 . On the other hand, emulsions containing ACSSNPs and ACSSNPs-CA were designed as E-NP and E-NP-CA, respectively.

\subsubsection{Stability and Characterization of Emulsions}

All emulsions were monitored visually at room temperature and at $40{ }^{\circ} \mathrm{C}$ to detect physical changes as phase separation or other instabilities for $120 \mathrm{~h}$, to ensure a suitable and stable emulsion for all further experiments. The viscosity of samples was determined using an HB Brookfield viscometer DV2T, at $200 \mathrm{rpm}$ and with needle No. 5. The form and size of the oil droplets was determined using an optical microscope. The emulsion color was evaluated by visual inspection $[63,64]$.

In order to evaluate the antioxidant capacity of ACSSNPs-CA in the emulsion under stress conditions, vitamin $\mathrm{E}$ was used as lipophilic model in the dispersed phase. Vitamin E consumption was determined using an HPLC method previously developed and validated [65]. To perform the analysis, $25 \mathrm{mg}$ of emulsion was mixed with $10 \mathrm{~mL}$ of isopropanol in a $50 \mathrm{~mL}$ volumetric flask. After this, the mixture was sonicated and diluted to required concentration with methanol. Subsequently, the sample was homogenized, filtered and measured by HPLC. The analysis was performed in a C-18 column with isocratic elution (methanol-water 97:3), pumped at a flow rate of $1.5 \mathrm{~mL} / \mathrm{min}$ and the injection volume was $50 \mu \mathrm{L}$. PDA detector was set at $290 \mathrm{~nm}$. The emulsion color was evaluated by visual inspection. 


\subsection{Statistical Analysis}

Results are expressed as means \pm standard deviation (SD) of a least three experiments using GraphPad Prism software version 6.01 (La Jolla, CA, USA).

\section{Results}

\subsection{Preparation and Characterization of ACSSNPS-CA}

A bifunctional (pigment and antioxidant) nanomaterial, based on silica superficially modified with carminic acid, was obtained. Initially, a uniform dense silica core with a diameter of $108 \mathrm{~nm}$ was prepared, which was then coated with a mesoporous silica using CTAB. After this, the surfactant was removed and nanoparticles with a hydrodynamic diameter of $162 \mathrm{~nm}$ were obtained (CSSNPs). The CSSNPs were amino-functionalized (with APTES, ACSSNPs) and then, carminic acid was immobilized onto the shell (Figure 1a). The porous shell thickness that allows the carminic acid linkage determined by TEM was $40 \mathrm{~nm}$. To activate the - $\mathrm{COOH}$ group of carminic acid, EDC/NHS cross-linking agent were used, which facilitates the reaction with the $-\mathrm{NH}_{2}$ group on the surface of the amino-functionalized nanoparticles, yielding an amide bond. The resulting spherical and homogeneous ACSSNPs-CA showed a diameter of about $175 \mathrm{~nm}$, determined by TEM images (Figure 1c) and DLS measurements. The zeta potential average of CSSNPs and ACSSNPs were $-33.5 \mathrm{mV}$ and $+2.8 \mathrm{mV}$, respectively. The difference is due to the successful modification of the $\mathrm{OH}$ groups of the porous shell when functionalized with amino groups. After immobilizing the carminic acid (CA) onto ACSSNPs, the zeta potential of the obtained nanosystem (ACSSNPs-CA) decreases to $-22.6 \mathrm{mV}$, showing a successful functionalization. TGA and HPLC results revealed that per each $100 \mathrm{mg}$ of nanoparticles, $4.24 \mathrm{mg}$ and $4.35 \mathrm{mg}$ of carminic acid were incorporated, respectively. An average value of $4.30 \mathrm{mg}$ was considered for all the experiments carried out.

Carminic acid linked to the nanoparticle (white powder) surface, confers them a purple color less intense than the characteristic red color of the carminic acid (Figure 1b). The presence of an amide bond was confirmed by FTIR. Typical of CSSNPs, the characteristic bands of ( $\equiv \mathrm{Si}-\mathrm{O}-\mathrm{Si} \equiv$ ) groups appear at $1200-1000 \mathrm{~cm}^{-1}$; in addition, bands at $2982 \mathrm{~cm}^{-1}$ and $2940 \mathrm{~cm}^{-1}$ that correspond to the stretching vibration of $-\mathrm{CH}_{2}$ present in the APTES propyl chain and the characteristic bending bands of $\mathrm{NH}_{2}$ group at $1518 \mathrm{~cm}^{-1}$ were observed for ACSSNPs. Furthermore, bands observed at $3300 \mathrm{~cm}^{-1}$ can be assigned to the stretching of the $\mathrm{OH}$ bond (adsorbed water). On the other hand, the ACSSNPs-CA spectrum additionally shows bands at $1638 \mathrm{~cm}^{-1}$ and $1544 \mathrm{~cm}^{-1}$ which correspond to amide-bond presence $[66,67]$. However, the best evidence of the successful conjugation of carminic acid was obtained when the nanomaterial was dispersed in solvents such as water, alkalized water ( $\mathrm{pH} 12)$, acidified water $(\mathrm{pH} 1)$ and ethanol. Subsequently, the samples were stirred at room temperature for six hours, centrifuged and then the supernatant analyzed by HPLC. The results did not show the presence of desorbed CA, unlike the control samples, consisting of CA adsorbed onto ACSSNPs, in which the CA was completely desorbed. 

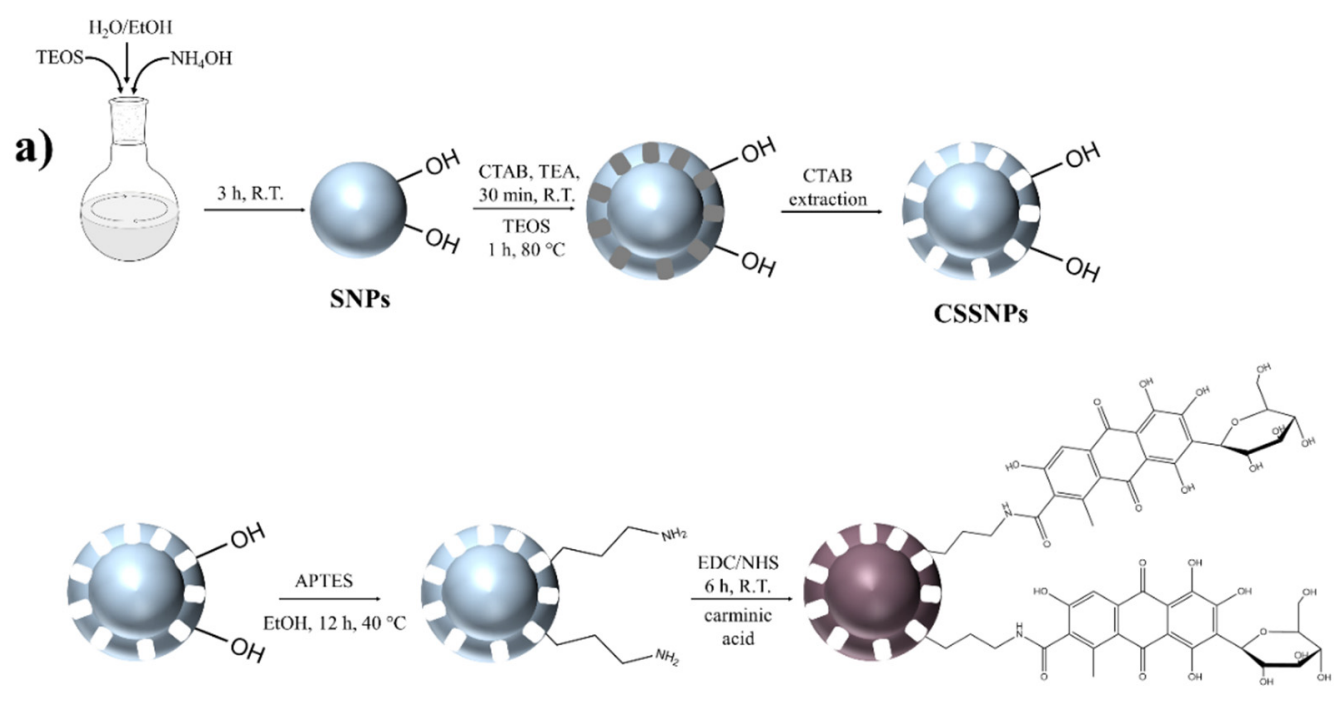

ACSSNPs

c)

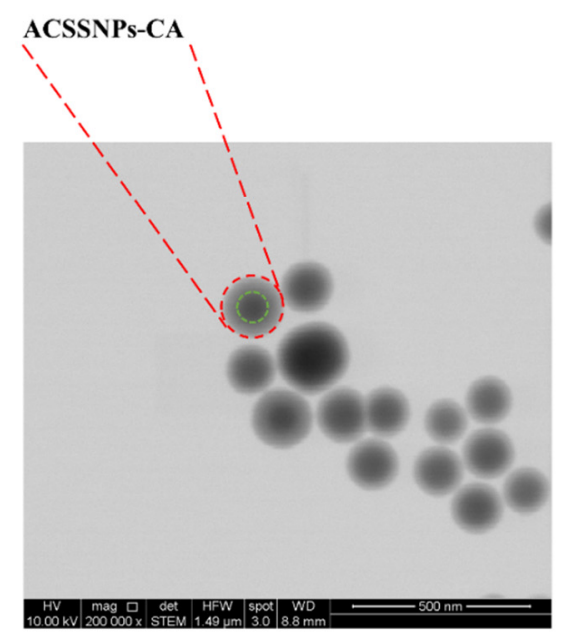

Figure 1. (a) Schematic illustration of the obtainment of amino-functionalized mesoporous core-shell silica nanoparticles with immobilized carminic acid (ACSSNPs-CA). (b) Powders of (i) carminic acid, (ii) ACSSNPs and (iii) ACSSNPs-CA. (c) TEM image of ACSSNs-CA.

\subsection{Antioxidant Capacity: Singlet Oxygen Quenching by ACSSNPs-CA}

Many pharmaceutical products are constantly exposed to degradation agents. For example, traces of transition metals such as copper or iron are presented in various pharmaceutical products and can produce free radicals by redox reactions with organic or inorganic substrates, molecular oxygen or hydroperoxides [68]. In particular, products such as emulsions applied to the skin are commonly exposed to UVA and UVB radiation, which generates harmful effects on the skin as well as on the applied products [69]. It is known that UVA radiation produces deleterious effects, since different chromophores in the skin or sensitizing drugs are able to generate several reactive oxygen species (ROS) [70-72], in which singlet oxygen plays a major role [73,74]. Therefore, studying the interaction between singlet oxygen and ACSSNPs-CA (CA covalently linked) is of great interest due to the potential deactivation effect of a ROS, which gives this hybrid nanosystem the functionality not only as an emulsion stabilizer and a pigment, but also as a product with antioxidant activity.

The amount of singlet oxygen monitored as infrared luminescence signal, decreased in the presence of free carminic acid and in the presence of ACSSNPs-CA. The sum of the physical quenching rate constant $\left(\mathrm{k}_{\mathrm{Q}}\right)$ and chemical reaction rate constant $\left(\mathrm{k}_{\mathrm{r}}\right)$ corresponds to the total quenching rate constant $\left(\mathrm{k}_{\mathrm{T}}\right)$. 
In acetone, the estimated value of $\mathrm{k}_{\mathrm{T}}$ for free $\mathrm{CA}$ was $6.35 \times 10^{7} \mathrm{M}^{-1} \mathrm{~s}^{-1}$ indicates that $\mathrm{CA}$ is able to quench singlet oxygen efficiently. The $\mathrm{CA}$ attached onto silica nanoparticles shows an enhanced singlet oxygen quenching $\left(\mathrm{k}_{\mathrm{T}}=1.30 \times 10^{8} \mathrm{M}^{-1} \mathrm{~s}^{-1}\right)$ compared to the free $\mathrm{CA}$, which is completely protonated under the experimental conditions.

In $\mathrm{D}_{2} 0$, the total quenching rate constants $\left(\mathrm{k}_{\mathrm{T}}\right)$ for CA and ACSSNPs-CA were $1.46 \times 10^{7} \mathrm{M}^{-1} \mathrm{~s}^{-1}$ and $1.67 \times 10^{8} \mathrm{M}^{-1} \mathrm{~s}^{-1}$ respectively, similar to those obtained in acetone.

This could be explained due to the partial ionization of CA in the obtained nanosystem, favored by the free amino groups on the nanoparticles that produce a CA phenolate form, which is capable to quench ${ }^{1} \mathrm{O}_{2}$ more efficiently than protonated CA. In addition, this is evidenced by a change of color from orange-red to intense purple, a characteristic color change when a violet tri-anionic molecule appears [75]. Another explanation could be the quenching effect of the silica matrix [76]; nevertheless, previously we reported that the effect in this nanosystem was not significant [42]. These results display a suitable antioxidant agent, the $\mathrm{k}_{\mathrm{T}}$ value of this nanomaterial is similar or even greater than the value reported for a few recognized antioxidants such as quercetin or morin $[77,78]$.

\subsection{Nanomaterial: Color Evaluation and Relation with Its Antioxidant Capacity}

To establish a direct correlation between color and remaining antioxidant capacity, a colorimetric determination was performed to ACSSNPs-CA under oxidative stress (oxidation with hydrogen peroxide) at $40{ }^{\circ} \mathrm{C} \pm 2{ }^{\circ} \mathrm{C}$ and $70 \% \mathrm{RH} \pm 5 \%$ for 5 days. At initial time, when ACSSNPs-CA is non oxidized, the red component $\left(a^{*} 22.67 \pm 0.18\right)$ is greater than the yellow component $\left(b^{*} 18.03 \pm 0.14\right)$. Both colorimetric parameters decrease linearly when the nanomaterial is oxidized with hydrogen peroxide for 1 to 5 days at $40 \pm 2{ }^{\circ} \mathrm{C}$ and $70 \% \mathrm{RH} \pm 5 \%$. After five days of undergoing highly oxidizing conditions, the NPs decreases its red color by $50 \%\left(a^{*} 11.95 \pm 0.10\right)$, increasing its brightness $\left(L^{*}\right)$ from $17.96 \pm 0.14$ at initial time to $31.22 \pm 0.25$ at five days. The color differences calculated $(\Delta \mathrm{E})$ were between $2.46 \pm 0.02$ and $7.70 \pm 0.06$, greater than the limit (1.5).

Figure 2 shows the relation between the colorimetric parameter $\left(\mathrm{a}^{*}\right)$ versus the antioxidant capacity of ACSSNPs-CA after oxidation with $\mathrm{H}_{2} \mathrm{O}_{2}$ at $40{ }^{\circ} \mathrm{C} \pm 2{ }^{\circ} \mathrm{C}$ and $70 \% \mathrm{RH} \pm 5 \%$ for five days. The antioxidant capacity was determined as the slope of the Stern-Volmer curve for the total quenching of singlet oxygen. The results show an exponential relation between both factors, where in addition to the obvious loss of color, the antioxidant capacity also decreases. However, the antioxidant capacity after five days under stress conditions is still significant $\left(2.60 \times 10^{7} \mathrm{M}^{-1} \mathrm{~s}^{-1}\right)$.

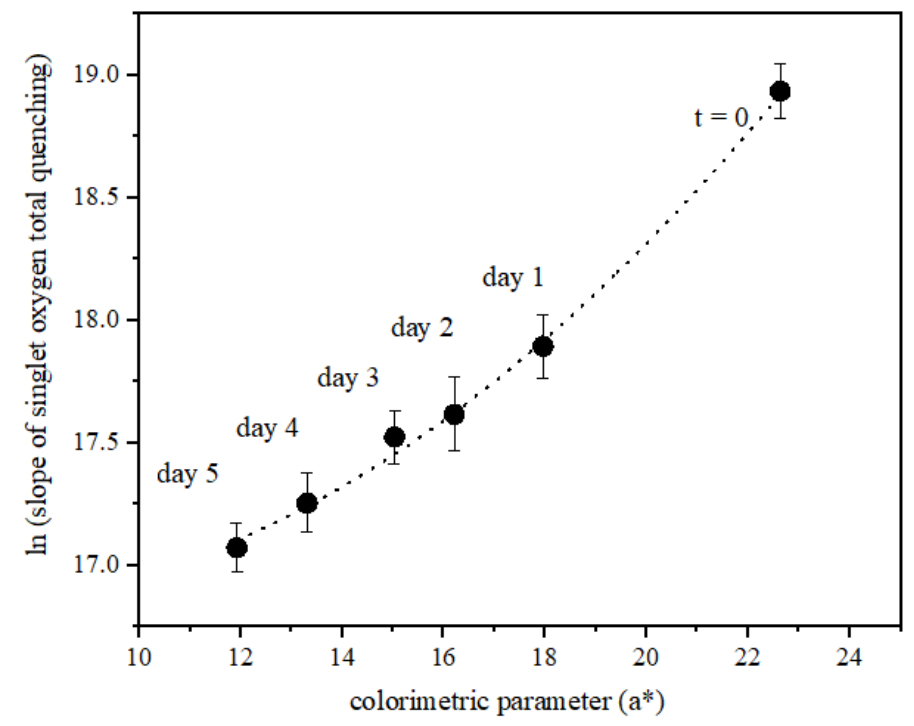

Figure 2. Relation between the colorimetric parameter $\left(\mathrm{a}^{*}\right)$ versus the antioxidant capacity of ACSSNPs-CA after oxidation with $\mathrm{H}_{2} \mathrm{O}_{2}$ at $40{ }^{\circ} \mathrm{C} \pm 2{ }^{\circ} \mathrm{C}$ and $70 \% \mathrm{RH} \pm 5 \%$ for five days. 


\subsection{ACSSNPs-CA Incorporation in O/W Emulsion: Stability of Vitamin E}

For oil-in-water (O/W) emulsions stabilized with surfactant; we used Tween 60 and Span 60, corresponding to a $30 \%$ of the oil phase. The selection of these surfactants is based on their known ability to stabilize $\mathrm{O} / \mathrm{W}$ pharmaceutical emulsions. The $\mathrm{pH}$ of all the emulsions was adjusted to $\mathrm{pH} 5$ using citric acid, considering that Binks et al. reported that the emulsification at neutral or alkaline $\mathrm{pH}$ stabilized with nanoparticles did not produce a stable emulsion $[79,80]$.

The stability of the emulsions was investigated under stress conditions (oxidation and temperature). Emulsions prepared with and without vitamin $\mathrm{E}$ and with and without nanoparticles were stored at $40^{\circ} \mathrm{C}$ for 24,48 and $120 \mathrm{~h}$ and were periodically analyzed.

The use of core-shell silica nanoparticles provides two great advantages. First, the solid core provides the required density to the nanoparticle to remain at the $\mathrm{O} / \mathrm{W}$ interface. Second, the mesoporous shell allows to immobilize more carminic acid on the surface, compared to a non-porous particle. Additionally, we carried out the incorporation of carminic acid onto silica nanoparticles, as a control sample, by physical adsorption using the impregnation method. However, the loaded amount of carminic acid adsorbed was less than that obtained by the immobilization technique (data not shown); therefore, no quantitative experiments were performed with this material.

A good physical stability of all emulsions was observed by optical microscopy analysis, confirming that the size of the drops has not changed (average diameter $20 \mu \mathrm{m}$ ), even after $120 \mathrm{~h}$ of storage at $40^{\circ} \mathrm{C}$. Emulsions were observed to be stable against phase separation or coalescence for $120 \mathrm{~h}$.

$\mathrm{O} / \mathrm{W}$ emulsions are particularly important systems for the administration of lipophilic bioactive compounds such as vitamin A and E, which are solubilized in the discontinuous phase [81]. In this work, we investigated the oxidative stability of vitamin E in the Pickering emulsions performed with ACSSNPs-CA, ACSSNPs and also with those stabilized by surfactants. HPLC analysis of vitamin E consumption was performed during an aging test under oxidative stress conditions by hydrogen peroxide, to verify chemical degradation. The results obtained from the recovery of vitamin $E$ from the prepared emulsions showed an excellent recovery (99.5\%) compared to a standard.

Vitamin E consumption was dependent on the type of emulsion (Figure 3). After $120 \mathrm{~h}$ at $40^{\circ} \mathrm{C}$, the percentage of vitamin E degradation when the emulsion was only stabilized with surfactants $(\mathrm{E}-0)$ was $24 \%$. However, the degradation decreases $14.5 \%$ when $1 \%$ ACSSNPs were incorporated into this emulsion (E-NP), demonstrating the protective effect of the nanoparticle film that forms on the surface of the oil droplets. However, a greater protective effect against of vitamin E oxidation was observed when the ACSSNPs-CA were incorporated (E-NP-CA), decreasing its consumption to $9.26 \%$ of the initial value. These results clearly show the antioxidant effect of ACSSNPs-CA system.

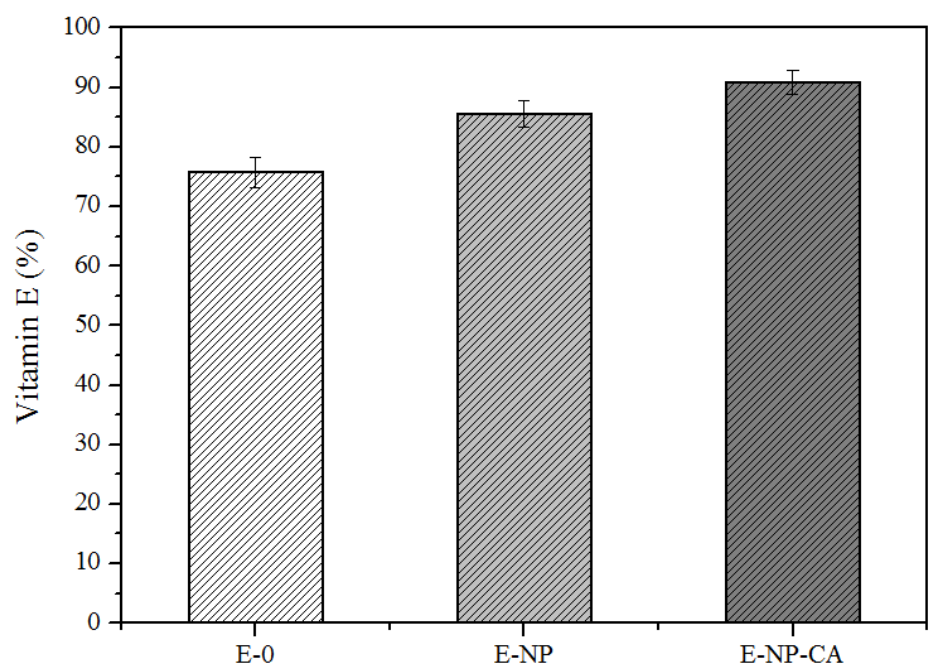

Figure 3. Vitamin E consumption in emulsions. Nanoparticle-free (E-0), with 1\% ACSSNPs (E-NP) and with $1 \%$ ACSSNPs-CA (E-NP-CA). Each point represents mean \pm SD $(n=3)$. 
The vitamin E degradation in emulsions under oxidative stress conditions at $40{ }^{\circ} \mathrm{C}$ for $120 \mathrm{~h}$ was evaluated. For this, $1.5 \%$ and $3 \%$ hydrogen peroxide was added to the emulsions. Vitamin $\mathrm{E}$ consumption in emulsion E-0 depends on the hydrogen peroxide concentration, decreasing $35.6 \%$ and $39 \%$ when the amount of $\mathrm{H}_{2} \mathrm{O}_{2}$ was $1.5 \%$ and $3 \%$, respectively. However, there is no dependence on the amount of $\mathrm{H}_{2} \mathrm{O}_{2}$ in emulsions E-NP and E-NP-CA, suggesting that NPs can hinder the oxidative species diffusion from aqueous medium to the oil droplet. Since all the emulsions were prepared with the same amount of emulsifiers, the size of the oil droplets was constant, so the stability of the vitamin $\mathrm{E}$ is only dependent on the absence or presence of the nanoparticles in the $\mathrm{O} / \mathrm{W}$ interphase. Studies show (Kargar et al.) [17,43] that silica nanoparticles reduce the oxidation rate of lipids of O/W emulsions in comparison with emulsions stabilized with Tween 20, because nanoparticles form an efficient physical barrier when they are located in the interphase of the drops, reducing the diffusion of oxidizing species. On the other hand, adding nanoparticles to emulsions increases the resistance of emulsion droplets to aggregation or coalescence, improving physical stability.

The susceptibility to oxidation of oils and lipids is a very important factor to consider in the quality, safety and efficacy of emulsions. The lipid peroxidation of emulsified lipids is a process of autoxidation through a free radical mechanism. The oxidation reaction starts when the free radicals abstract a hydrogen atom from a methylene of the fatty acid chain, the products of this reaction are mainly hydroperoxides [82-85]. In our work, the oil phase is composed of mineral oil and castor oil. The main component of castor oil is ricinoleic acid, a monounsaturated fatty acid of 18 carbons. In comparison with other oils commonly used in pharmaceutical, food and/or cosmetic emulsions, castor oil provides greater oxidative stability against peroxidation due to the presence of a hydroxyl group, beta to the double bond [86].

Vitamin E ( $\alpha$-tocopherol) is one of the best compounds in dermatological formulation for the treatment of skin aging. It is a lipid-soluble antioxidant that plays key roles in protecting cell membranes from lipid peroxidation by free radicals and in reducing photocarcinogesis [87]. Thiele et al. concluded that $\alpha$-tocopherol is the major antioxidant in the human epidermis, and its depletion is an early and sensitive marker of environmental oxidative damage [88]. Vitamin $\mathrm{E}$ is present as the free alcohol or in its ester forms, and the beneficial effects of vitamin E-containing emulsions depend on the added concentration as well as its stability. The $\mathrm{OH}$ radical attacks vitamin $\mathrm{E}$ through different pathways: hydrogen abstraction reactions from the phenolic $\mathrm{O}-\mathrm{H}$ and methyl groups and electrophilic $\mathrm{OH}$ addition on several positions on the aromatic ring. The most favorable pathways are the hydrogen abstraction reaction from the phenolic hydrogen and the electrophilic addition to the aromatic ring. Espinosa-García et al. proposed that the final rate constant $\left(2.7 \times 10^{8} \mathrm{M}^{-1} \mathrm{~s}^{-1}\right.$ at $\left.298 \mathrm{~K}\right)$ results from the combination of the competitive hydrogen abstraction and the addition reactions, where hydrogen abstraction represents only a $20 \%$ of the total $\mathrm{OH}$ radical reaction [89]. On the other hand, tocopherol can also act as an efficient quencher of singlet oxygen $\left({ }^{1} \mathrm{O}_{2}\right)$. Sies et al. compared values of absolute second-order rate constants for the physical quenching $\left(\mathrm{k}_{\mathrm{Q}}\right)$ and chemical reaction $\left(\mathrm{k}_{\mathrm{r}}\right)$ of $\alpha, \beta, \gamma$ and $\delta$ tocopherols with ${ }^{1} \mathrm{O}_{2}$ in ethanol. They found that the overall rate constants $\left(\mathrm{k}_{\mathrm{T}}=\mathrm{k}_{\mathrm{Q}}+\mathrm{k}_{\mathrm{r}}\right)$ decrease in the order $\alpha>\gamma>\delta>\beta$-tocopherol [90]. Fukuzawa et al. reported that the oxidation rates of $\alpha$-tocopherol by singlet oxygen depend on the photosensitizing pigment and the membrane charge of liposomes, also, the results in ethanol solutions were compared. In ethanol, using methylene blue (MB) as sensitizer, the order of physical quenching rate $\left(\mathrm{k}_{\mathrm{Q}}=3.1 \times 10^{8} \mathrm{M}^{-1} \mathrm{~s}^{-1}\right)$ is similar to the chemical reaction rate $\left(\mathrm{k}_{\mathrm{r}}=1.4 \times 10^{8} \mathrm{M}^{-1} \mathrm{~s}^{-1}\right)$ [91].

\subsection{Color Evaluation in Pickering Emulsions with ACSSNPs-CA}

The CA and nanosystems were dispersed in different solvents used in typical pharmaceutical formulation, and the absorption spectra (Figure 4) of CA in ethanol (A, black line) and ACSSNPs-CA dispersed in mineral oil (B, red line) and aqueous solution of $5 \%$ glycerin $(C$, blue line) were recorded. Typically, the absorption spectra of carminic acid in ethanol and solvents, such as water at neutral $\mathrm{pH}$, show an acute peak at $278 \mathrm{~nm}$ corresponding to the $\pi \rightarrow \pi^{*}$ transition and another band centered at 
$500 \mathrm{~nm}$ corresponding to the $\mathrm{n} \rightarrow \pi^{*}$ transition. Nanoparticles dispersed in nonpolar solvents, such as mineral oil, show bands similar to carminic acid in ethanol, however, when the nanoparticles are dispersed in protic polar solvents such as water or ethanol, a significant bathochromic shift with a maximum at $550 \mathrm{~nm}$ was observed [92]. One explanation is that the free amino groups in the shell of the nanoparticle after the amino-functionalization of bare core-shell silica nanoparticles, alkalinize the surface microenvironment, ionizing the hydroxyl groups of the attached carminic acid, producing the typical shift observed in alkaline solutions. When the carminic acid is attached onto nanoparticles, the intensity of its absorption spectrum decreases independently of the dispersion solvent.

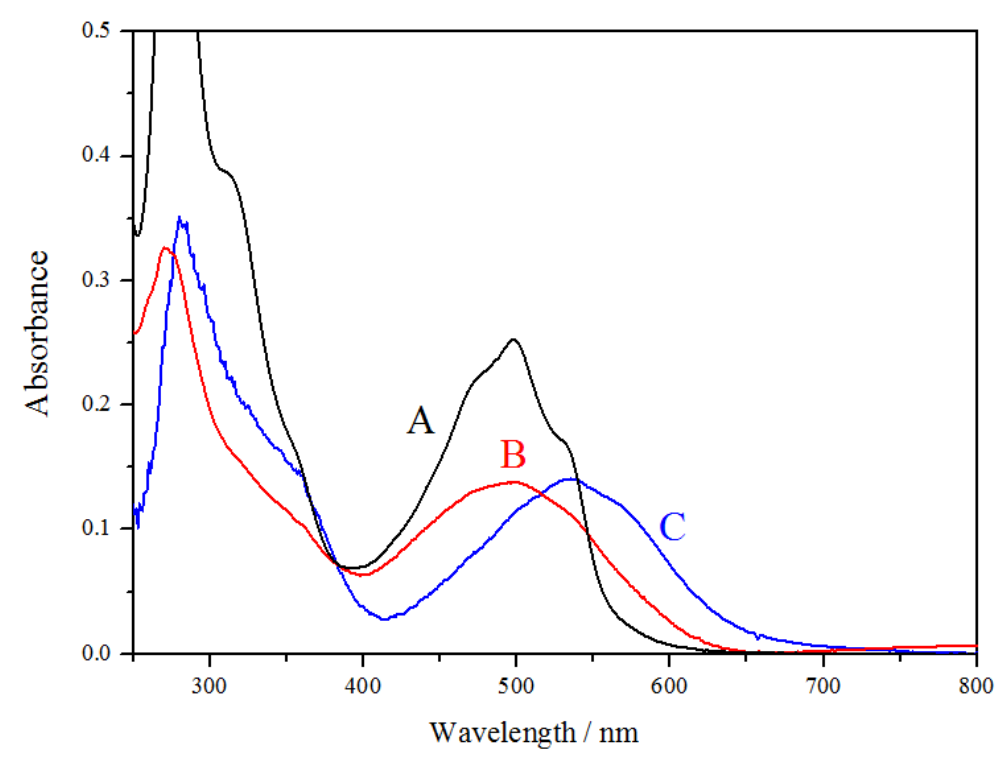

Figure 4. UV-vis spectra of (A) carminic acid (CA) in ethanol, (B) ACSSNPs-CA dispersed in mineral oil, and (C) ACSSNPs-CA dispersed in aqueous solution of $5 \%$ glycerin, at $35 \mu \mathrm{M}$.

The color changes were evidenced by the addition of NPs to emulsions stabilized with surfactants (Figure 5a). The incorporation of 1\% ACSSNPs does not produce changes in the color of the emulsion, however, a notorious change of color is observed by the addition of $0.1 \%, 0.5 \%$ and $1 \%$ of ACSSNPs-CA.

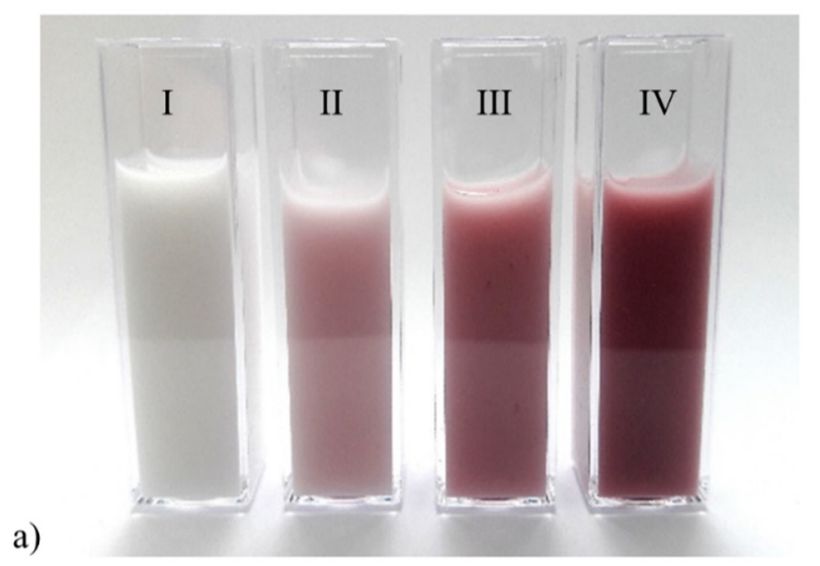

b)

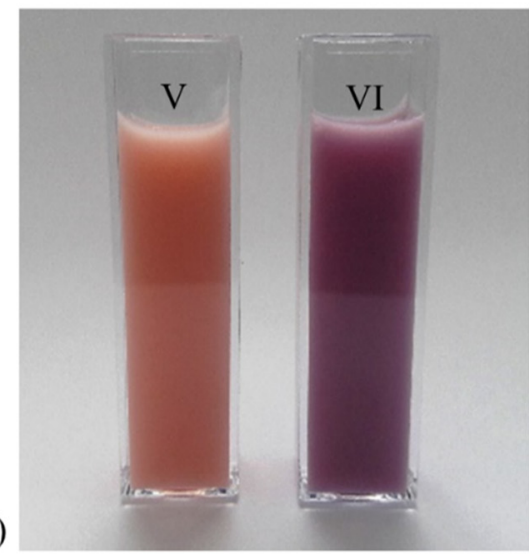

Figure 5. Color of emulsions with ACSSNPs and ACSSNPs-CA incorporated. (a) Incorporation of 1\% ACSSNPs (I) and $0.1 \%$ (II), $0.5 \%$ (III) and $1 \%$ of ACSSNPs-CA (IV). (b) Incorporation of $1 \%$ ACSSNPs-CA adjusted to $\mathrm{pH} 3(\mathrm{~V})$ and adjusted to $\mathrm{pH} 9$ (VI).

The Pickering emulsions with ACSSNPs-CA (Figure 5b) were stable immediately when the $\mathrm{pH}$ was adjusted to acid ( $\mathrm{pH} 3$ ) and basic ( $\mathrm{pH} 9)$, however, a color change was observed. This change is due 
to the color change shown by the carminic acid linked to the surface of the nanoparticles. The carminic acid is a red pigment soluble in water in both acid and alkaline solutions and its color is very sensitive to $\mathrm{pH}$, its appearance occurring at $\mathrm{pH} 7-7.7$, light red to red and at basic $\mathrm{pH}$ of magenta. Carminic acid has an even lower coefficient of absorbance at $\mathrm{pH} 1$, its pale orange color occurring at $\mathrm{pHs}$ below $4.5[4,93]$.

\section{Conclusions}

A bifunctional pigment-antioxidant nanomaterial based carminic acid covalently linked onto a silica nanoparticle to confer color and improved oxidative stability to cosmetic Pickering emulsions was obtained. To achieve this purpose, a uniform dense silica core was prepared, which was then coated with mesoporous silica that was amino-functionalized and then carminic acid was attached through the action of coupling EDC/NHS agents. We obtained a spherical and homogeneous nanosystem (ACSSNPs-CA) with a diameter close to $175 \mathrm{~nm}$. The results revealed that an average value of $4.30 \mathrm{mg}$ of carminic acid was attached per $100 \mathrm{mg}$ of nanoparticles.

A significant change of emulsion color was observed by the addition of ACSSNPs-CA. At pH 5, samples showed an attractive pink color and when the acidity was adjusted to $\mathrm{pH} 3$ and $\mathrm{pH}$, a change in color was observed, similarly carminic acid in solution. When the colorimetric parameters and the antioxidant capacity of ACSSNPs-CA under oxidative stress were evaluated, both dropped, following a direct relation. Despite this decrease, antioxidant activity remained significant, suggesting the reuse properties of the nanomaterial.

The incorporation of nanoparticles without carminic acid notably improved the chemical stability of emulsion. However, the best protective effect against vitamin E oxidation was observed when the ACSSNPs-CA were present. A significant reduction of its consumption (only a $9.26 \%$ of the initial value), demonstrates the antioxidant effect of this new nanosystem.

In summary, the changes in the coloration of our bifunctional pigment/antioxidant nano-excipient are a good indication of the remaining antioxidant activity of this nanomaterial and the loss of pH-dependent stability of emulsion. These easy-to-detect properties make this system a useful tool for use in formulations for food, cosmetic and/or pharmaceutical applications.

Author Contributions: Conceptualization, J.M., G.G. and F.A.; methodology, J.M., C.U. and F.A; software, J.M., G.G. and F.A.; validation, J.M., C.U. and F.A.; formal analysis, J.M., G.G. and F.A.; investigation, J.M., G.G., C.U., M.A.L., V.G.-H., S.N. and F.A.; resources, J.M, F.A. and S.N.; data curation, J.M., G.G., V.G. and F.A.; writing-original draft preparation, J.M., G.G., S.N. and F.A.; writing-review and editing, J.M., G.G. and F.A.; visualization, J.M., G.G. and F.A.; supervision, J.M., G.G. and F.A.; project administration, J.M. and F.A.; funding acquisition, J.M., S.N. and F.A. All authors have read and agreed to the published version of the manuscript.

Funding: This work was supported by grants of the Chilean CONICYT (FONDECYT 1160757 and CONICYT 21160932), Universidad de Chile-PII2019 and the Spanish Ministerio de Economía y Competitividad (CTQ2016-78454-C2-1-R).

Conflicts of Interest: The authors declare no conflict of interest.

\section{References}

1. Chantrapornchai, W.; Clydesdale, F.M.; Julian Mcclements, D. Understanding colors in emulsions. In Proceedings of the ACS Symposium Series; American Chemical Society: Washington DC, USA, 2008; pp. 364-387.

2. Weisz, A.; Milstein, S.R.; Scher, A.L.; Hepp, N.M. Colouring agents in cosmetics: Regulatory aspects and analytical methods. In Analysis of Cosmetic Products; Elsevier: Amsterdam, The Netherlands, 2018; pp. 123-157.

3. Dapson, R. The history, chemistry and modes of action of carmine and related dyes. Biotech. Histochem. 2007, 82, 173-187. [CrossRef] [PubMed]

4. Dapson, R. A method for determining identity and relative purity of carmine, carminic acid and aminocarminic acid. Biotech. Histochem. 2005, 80, 201-205. [CrossRef] [PubMed] 
5. Pierlot, C.; Nardello, V.; Schmidt, R.; Aubry, J.-M. Determination of physical (kq) and chemical (kr) rate constants for singlet oxygen quenching using the thermolysis of a naphthalenic endoperoxide in $\mathrm{H} 2 \mathrm{O}$ and D2O. Arkivoc 2007, 8, 245-256.

6. Lev-Goldman, V.; Mester, B.; Ben-Aroya, N.; Hanoch, T.; Rupp, B.; Stanoeva, T.; Gescheidt, G.; Seger, R.; Koch, Y.; Weiner, L. Conjugates of gonadotropin releasing hormone (GnRH) with carminic acid: Synthesis, generation of reactive oxygen species (ROS) and biological evaluation. Bioorg. Med. Chem. 2008, 16, 6789-6798. [CrossRef]

7. Machatova, Z.; Barbierikova, Z.; Poliak, P.; Jančovičová, V.; Lukeš, V.; Brezova, V. Study of natural anthraquinone colorants by epr and uv/vis spectroscopy. Dyes Pigments 2016, 132, 79-93. [CrossRef]

8. González, E.A.; García, E.M.; Nazareno, M.A. Free radical scavenging capacity and antioxidant activity of cochineal (Dactylopius coccus C.) extracts. Food Chem. 2010, 119, 358-362.

9. Sharma, T.; Kumar, G.S.; Chon, B.H.; Sangwai, J.S. Thermal stability of oil-in-water Pickering emulsion in the presence of nanoparticle, surfactant, and polymer. J. Ind. Eng. Chem. 2015, 22, 324-334. [CrossRef]

10. Zhang, S.; Zhou, Y.; Yang, C. Pickering emulsions stabilized by the complex of polystyrene particles and chitosan. Colloids Surf. A Physicochem. Eng. Asp. 2015, 482, 338-344. [CrossRef]

11. Worthen, A.J.; Foster, L.M.; Dong, J.; Bollinger, J.A.; Peterman, A.H.; Pastora, L.E.; Bryant, S.L.; Truskett, T.M.; Bielawski, C.W.; Johnston, K.P. Synergistic Formation and Stabilization of Oil-in-Water Emulsions by a Weakly Interacting Mixture of Zwitterionic Surfactant and Silica Nanoparticles. Langmuir 2014, 30, 984-994. [CrossRef]

12. Vílchez, A.; Rodríguez-Abreu, C.; Menner, A.; Bismarck, A.; Esquena, J. Antagonistic Effects between Magnetite Nanoparticles and a Hydrophobic Surfactant in Highly Concentrated Pickering Emulsions. Langmuir 2014, 30, 5064-5074. [CrossRef]

13. Midmore, B.R. Preparation of a novel silica-stabilized oil/water emulsion. Colloids Surf. A Physicochem. Eng. Asp. 1998, 132, 257-265. [CrossRef]

14. Frelichowska, J.; Bolzinger, M.-A.; Chevalier, Y. Pickering emulsions with bare silica. Colloids Surf. A Physicochem. Eng. Asp. 2009, 343, 70-74. [CrossRef]

15. Lam, S.; Velikov, K.P.; Velev, O.D. Pickering stabilization of foams and emulsions with particles of biological origin. Curr. Opin. Colloid Interface Sci. 2014, 19, 490-500. [CrossRef]

16. Marto, J.; Gouveia, L.; Jorge, I.M.; Duarte, A.; Gonçalves, L.M.; Silva, S.M.C.; Antunes, F.; Pais, A.A.C.C.; Oliveira, E.; Almeida, A.J.; et al. Starch-based Pickering emulsions for topical drug delivery: A QbD approach. Colloids Surf. B Biointerfaces 2015, 135, 183-192. [CrossRef] [PubMed]

17. Kargar, M.; Spyropoulos, F.; Norton, I.T. Microstructural design to reduce lipid oxidation in oil-inwater emulsions. Procedia Food Sci. 2011, 1, 104-108. [CrossRef]

18. Rayner, M.; Marku, D.; Eriksson, M.; Sjöö, M.; Dejmek, P.; Wahlgren, M. Biomass-based particles for the formulation of Pickering type emulsions in food and topical applications. Colloids Surf. A Physicochem. Eng. Asp. 2014, 458, 48-62. [CrossRef]

19. Binks, B.P.; Lumsdon, S.O. Influence of Particle Wettability on the Type and Stability of Surfactant-Free Emulsions. Langmuir 2000, 16, 8622-8631. [CrossRef]

20. Binks, B.P.; Isa, L.; Tyowua, A.T. Direct Measurement of Contact Angles of Silica Particles in Relation to Double Inversion of Pickering Emulsions. Langmuir 2013, 29, 4923-4927. [CrossRef]

21. Kawazoe, A.; Kawaguchi, M. Characterization of silicone oil emulsions stabilized by TiO2 suspensions pre-adsorbed SDS. Colloids Surf. A Physicochem. Eng. Asp. 2011, 392, 283-287. [CrossRef]

22. Zhang, J.; Li, L.; Xu, J.; Sun, D. Effect of cetyltrimethylammonium bromide addition on the emulsions stabilized by montmorillonite. Colloid Polym. Sci. 2014, 292, 441-447. [CrossRef]

23. Wang, J.; Yang, F.; Tan, J.; Liu, G.; Xu, J.; Sun, D. Pickering Emulsions Stabilized by a Lipophilic Surfactant and Hydrophilic Platelike Particles. Langmuir 2010, 26, 5397-5404. [CrossRef] [PubMed]

24. Kpogbemabou, D.; Lecomte-Nana, G.; Aimable, A.; Bienia, M.; Niknam, V.; Carrion, C. Oil-in-water Pickering emulsions stabilized by phyllosilicates at high solid content. Colloids Surf. A Physicochem. Eng. Asp. 2014, 463, 85-92. [CrossRef]

25. Nikfarjam, N.; Taheri Qazvini, N.; Deng, Y. Surfactant free Pickering emulsion polymerization of styrene in w/o/w system using cellulose nanofibrils. Eur. Polym. J. 2015, 64, 179-188. [CrossRef]

26. Yan, H.; Zhao, B.; Long, Y.; Zheng, L.; Tung, C.-H.; Song, K. New pickering emulsions stabilized by silica nanowires. Colloids Surf. A Physicochem. Eng. Asp. 2015, 482, 639-646. [CrossRef] 
27. Tikekar, R.V.; Pan, Y.; Nitin, N. Fate of curcumin encapsulated in silica nanoparticle stabilized Pickering emulsion during storage and simulated digestion. Food Res. Int. 2013, 51, 370-377. [CrossRef]

28. Wang, S.; He, Y.; Zou, Y. Study of Pickering emulsions stabilized by mixed particles of silica and calcite. Particuology 2010, 8, 390-393. [CrossRef]

29. Bongur, R.; Le Nouen, D.; Gaslain, F.; Marichal, C.; Lebeau, B.; Guarilloff, P. Red 33 dye co-encapsulated with cetyltrimethylammonium in mesoporous silica materials. Dyes Pigments 2016, 127, 1-8. [CrossRef]

30. Oluwole, D.O.; Nyokong, T. Photophysicochemical behaviour of metallophthalocyanines when doped onto silica nanoparticles. Dyes Pigments 2017, 136, 262-272. [CrossRef]

31. Mutneja, R.; Singh, R.; Kaur, V.; Wagler, J.; Kroke, E. Development of new precursors for immobilizing dyes onto silica surfaces. Dyes Pigments 2014, 108, 41-49. [CrossRef]

32. López Zeballos, N.C.; García Vior, M.C.; Awruch, J.; Dicelio, L.E. A comparative study of peripheral and non-peripheral zinc (II) phthalocyanines incorporated into mesoporous silica nanoparticles. Dyes Pigments 2015, 113, 145-150. [CrossRef]

33. Vallet-Regi, M.; Rámila, A.; del Real, R.P.; Pérez-Pariente, J. A New Property of MCM-41: Drug Delivery System. Chem. Mater. 2001, 13, 308-311. [CrossRef]

34. Tzankov, B.; Tzankova, V.; Aluani, D.; Yordanov, Y.; Spassova, I.; Kovacheva, D.; Avramova, K.; Valoti, M.; Yoncheva, K. Development of MCM-41 mesoporous silica nanoparticles as a platform for pramipexole delivery. J. Drug Deliv. Sci. Technol. 2019, 51, 26-35. [CrossRef]

35. Korzeniowska, A.; Strzempek, W.; Makowski, W.; Menaszek, E.; Roth, W.J.; Gil, B. Incorporation and release of a model drug, ciprofloxacin, from non-modified SBA-15 molecular sieves with different pore sizes. Microporous Mesoporous Mater. 2020, 294, 109903. [CrossRef]

36. Esperanza Adrover, M.; Pedernera, M.; Bonne, M.; Lebeau, B.; Bucalá, V.; Gallo, L. Synthesis and characterization of mesoporous SBA-15 and SBA-16 as carriers to improve albendazole dissolution rate. Saudi Pharm. J. 2020, 28, 15-24. [CrossRef] [PubMed]

37. Daneluti, A.L.M.; Neto, F.M.; Ruscinc, N.; Lopes, I.; Robles Velasco, M.V.; Do Rosário Matos, J.; Baby, A.R.; Kalia, Y.N. Using ordered mesoporous silica SBA-15 to limit cutaneous penetration and transdermal permeation of organic UV filters. Int. J. Pharm. 2019, 570, 118633. [CrossRef] [PubMed]

38. Ahmed, K.; Rehman, F.; Pires, C.T.G.V.M.T.; Rahim, A.; Santos, A.L.; Airoldi, C. Aluminum doped mesoporous silica SBA-15 for the removal of remazol yellow dye from water. Microporous Mesoporous Mater. 2016, 236, 167-175. [CrossRef]

39. Gallardo, A.; Morales, J.; Comas-Barceló, J.; Gallavardin, T.; Acedo, P.; Villanueva, A.; Nonell, S. 20-Silica-based nanostructured materials for biomedical applications. In Applications of Nanoscience in Photomedicine; Hamblin, M.R., Avci, P., Eds.; Chandos Publishing: Oxford, UK, 2015; pp. 429-448. [CrossRef]

40. Arriagada, F.; Correa, O.; Günther, G.; Nonell, S.; Mura, F.; Olea-Azar, C.; Morales, J. Morin Flavonoid Adsorbed on Mesoporous Silica, a Novel Antioxidant Nanomaterial. PLoS ONE 2016, 11, e0164507. [CrossRef]

41. Berlier, G.; Gastaldi, L.; Ugazio, E.; Miletto, I.; Iliade, P.; Sapino, S. Stabilization of quercetin flavonoid in MCM-41 mesoporous silica: Positive effect of surface functionalization. J. Colloid Interface Sci. 2013, 393, 109-118. [CrossRef]

42. Arriagada, F.; Günther, G.; Nos, J.; Nonell, S.; Olea-Azar, C.; Morales, J. Antioxidant Nanomaterial Based on Core-Shell Silica Nanospheres with Surface-Bound Caffeic Acid: A Promising Vehicle for Oxidation-Sensitive Drugs. Nanomaterials 2019, 9, 214. [CrossRef]

43. Kargar, M.; Spyropoulos, F.; Norton, I.T. The effect of interfacial microstructure on the lipid oxidation stability of oil-in-water emulsions. J. Colloid Interface Sci. 2011, 357, 527-533. [CrossRef]

44. Guillermin, D.; Debroise, T.; Trigueiro, P.; de Viguerie, L.; Rigaud, B.; Morlet-Savary, F.; Balme, S.; Janot, J.-M.; Tielens, F.; Michot, L.; et al. New pigments based on carminic acid and smectites: A molecular investigation. Dyes Pigments 2019, 160, 971-982. [CrossRef]

45. Bujdák, J. Hybrid systems based on organic dyes and clay minerals: Fundamentals and potential applications. Clay Miner. 2018, 50, 549-571. [CrossRef]

46. Pérez, E.; Ibarra, I.A.; Guzmán, A.; Lima, E. Hybrid pigments resulting from several guest dyes onto $\gamma$-alumina host: A spectroscopic analysis. Spectrochim. Acta Part A Mol. Biomol. Spectrosc. 2017, 172, $174-181$. [CrossRef] [PubMed] 
47. Jamikorn, S.; Vivekaphirat, S.; Somsongkul, V.; Suanthaisong, W.; Naikaew, A.; Wongchaisuwat, A.; Arunchaiya, M. Dye-sensitized Solar Cell Based on Composite Poly (ethylene oxide) Electrolyte with Natural Carmine Pigment. Chiang Mai J. Sci. 2016, 43, 1113-1121.

48. Martínez-Zapata, O.; Méndez-Vivar, J.; Bosch, P.; Lara, V.H. Synthesis and characterization of amorphous aluminosilicates prepared by sol-gel to encapsulate organic dyes. J. Non-Cryst. Solids 2011, 357, 3480-3485. [CrossRef]

49. Larese Filon, F.; Mauro, M.; Adami, G.; Bovenzi, M.; Crosera, M. Nanoparticles skin absorption: New aspects for a safety profile evaluation. Regul. Toxicol. Pharmacol. 2015, 72, 310-322. [CrossRef]

50. Hirai, T.; Yoshikaw, T.; Nabeshi, H.; Yoshid, T.; Akase, T.; Yoshiok, Y.; Itoh, N.; Tsutsumi, Y. Dermal absorption of amorphous nanosilica particles after topical exposure for three days. Die Pharm.-Int. J. Pharm. Sci. 2012, 67, 742-743. [CrossRef]

51. Staroňová, K.; Nielsen, J.B.; Roursgaard, M.; Knudsen, L.E. Transport of SiO2 Nanoparticles through Human Skin. Basic Clin. Pharmacol. Toxicol. 2012, 111, 142-144. [CrossRef]

52. Ostrowski, A.; Nordmeyer, D.; Boreham, A.; Brodwolf, R.; Mundhenk, L.; Fluhr, J.W.; Lademann, J.; Graf, C.; Ruhl, E.; Alexiev, U.; et al. Skin barrier disruptions in tape stripped and allergic dermatitis models have no effect on dermal penetration and systemic distribution of AHAPS-functionalized silica nanoparticles. Nanomedicine 2014, 10, 1571-1581. [CrossRef]

53. Rancan, F.; Gao, Q.; Graf, C.; Troppens, S.; Hadam, S.; Hackbarth, S.; Kembuan, C.; Blume-Peytavi, U.; Rühl, E.; Lademann, J.; et al. Skin Penetration and Cellular Uptake of Amorphous Silica Nanoparticles with Variable Size, Surface Functionalization, and Colloidal Stability. ACS Nano 2012, 6, 6829-6842. [CrossRef]

54. Stöber, W.; Fink, A.; Bohn, E. Controlled growth of monodisperse silica spheres in the micron size range. J. Colloid Interface Sci. 1968, 26, 62-69. [CrossRef]

55. Ha, S.W.; Camalier, C.E.; Beck, G.R., Jr.; Lee, J.K. New method to prepare very stable and biocompatible fluorescent silica nanoparticles. Chem. Commun. 2009, 2881-2883. [CrossRef] [PubMed]

56. Chen, F.; Hong, H.; Shi, S.; Goel, S.; Valdovinos, H.F.; Hernandez, R.; Theuer, C.P.; Barnhart, T.E.; Cai, W. Engineering of hollow mesoporous silica nanoparticles for remarkably enhanced tumor active targeting efficacy. Sci. Rep. 2014, 4, 5080. [CrossRef] [PubMed]

57. Grabarek, Z.; Gergely, J. Zero-length crosslinking procedure with the use of active esters. Anal. Biochem. 1990, 185, 131-135. [CrossRef]

58. Jiménez-Banzo, A.; Ragàs, X.; Kapusta, P.; Nonell, S. Time-resolved methods in biophysics. 7. Photon counting vs. analog time-resolved singlet oxygen phosphorescence detection. Photochem. Photobiol. Sci. 2008, 7, 1003-1010. [CrossRef]

59. Nonell, S.; Braslavsky, S.E. [4] Time-resolved singlet oxygen detection. In Methods in Enzymology; Academic Press: Cambridge, MA, USA, 2000; Volume 319, pp. 37-49.

60. Rhee, Y.-S.; Park, C.-W.; Shin, Y.-S.; Kam, S.-H.; Lee, K.-H.; Park, E.-S. Application of instrumental evaluation of color for the pre-formulation and formulation of rabeprazole. Int. J. Pharm. 2008, 350, 122-129. [CrossRef]

61. Stark, G.; Fawcett, J.P.; Tucker, I.G.; Weatherall, I.L. Instrumental evaluation of color of solid dosage forms during stability testing. Int. J. Pharm. 1996, 143, 93-100. [CrossRef]

62. Verkempinck, S.H.E.; Kyomugasho, C.; Salvia-Trujillo, L.; Denis, S.; Bourgeois, M.; Van Loey, A.M.; Hendrickx, M.E.; Grauwet, T. Emulsion stabilizing properties of citrus pectin and its interactions with conventional emulsifiers in oil-in-water emulsions. Food Hydrocoll. 2018, 85, 144-157. [CrossRef]

63. Kowalska, M.; Ziomek, M.; Żbikowska, A. Stability of cosmetic emulsion containing different amount of hemp oil. Int. J. Cosmet. Sci. 2015, 37, 408-416. [CrossRef]

64. Ahuja, A.; Iqbal, A.; Iqbal, M.; Lee, J.W.; Morris, J.F. Rheology of Hydrate-Forming Emulsions Stabilized by Surfactant and Hydrophobic Silica Nanoparticles. Energy Fuels 2018, 32, 5877-5884. [CrossRef]

65. Nada, A.; Krishnaiah, Y.S.R.; Zageloul, A.A.; Khattab, I. Analysis of vitamin E in commercial cosmetic preparations by HPLC. J. Cosmet. Sci. 2010, 61, 353-365. [PubMed]

66. Deligiannakis, Y.; Sotiriou, G.A.; Pratsinis, S.E. Antioxidant and antiradical SiO2 nanoparticles covalently functionalized with gallic acid. ACS Appl. Mater. Interfaces 2012, 4, 6609-6617. [CrossRef] [PubMed]

67. Berlier, G.; Gastaldi, L.; Sapino, S.; Miletto, I.; Bottinelli, E.; Chirio, D.; Ugazio, E. MCM-41 as a useful vector for rutin topical formulations: Synthesis, characterization and testing. Int. J. Pharm. 2013, 457, 177-186. [CrossRef] [PubMed] 
68. Hovorka, S.W.; Schöneich, C. Oxidative degradation of pharmaceuticals: Theory, mechanisms and inhibition. J. Pharm. Sci. 2001, 90, 253-269. [CrossRef]

69. Tyrrell, R.M. Modulation of gene expression by the oxidative stress generated in human skin cells by UVA radiation and the restoration of redox homeostasis. Photochem. Photobiol. Sci. 2012, 11, 135-147. [CrossRef]

70. Young, A.R. Chromophores in human skin. Phys. Med. Biol. 1997, 42, 789-802. [CrossRef]

71. de Jager, T.L.; Cockrell, A.E.; Du Plessis, S.S. Ultraviolet Light Induced Generation of Reactive Oxygen Species. In Ultraviolet Light in Human Health, Diseases and Environment; Ahmad, S.I., Ed.; Springer International Publishing: Cham, Switzerland, 2017; pp. 15-23. [CrossRef]

72. Liebel, F.; Kaur, S.; Ruvolo, E.; Kollias, N.; Southall, M.D. Irradiation of Skin with Visible Light Induces Reactive Oxygen Species and Matrix-Degrading Enzymes. J. Investig. Dermatol. 2012, 132, 1901-1907. [CrossRef]

73. Nonell, S.; García-Díaz, M.; Viladot, J.L.; Delgado, R. Singlet molecular oxygen quenching by the antioxidant dimethylmethoxy chromanol in solution and in ex vivo porcine skin. Int. J. Cosmet. Sci. 2013, 35, 272-280. [CrossRef]

74. Baier, J.; Maisch, T.; Maier, M.; Engel, E.; Landthaler, M.; Bäumler, W. Singlet Oxygen Generation by UVA Light Exposure of Endogenous Photosensitizers. Biophys. J. 2006, 91, 1452-1459. [CrossRef]

75. Marzec, A.; Szadkowski, B.; Rogowski, J.; Maniukiewicz, W.; Moszyński, D.; Rybiński, P.; Zaborski, M. Carminic acid stabilized with aluminum-magnesium hydroxycarbonate as new colorant reducing flammability of polymer composites. Molecules 2019, 24, 560. [CrossRef]

76. Boix-Garriga, E.; Rodríguez-Amigo, B.; Planas, O.; Nonell, S. Chapter 2: Properties of Singlet Oxygen. In Singlet Oxygen: Applications in Biosciences and Nanosciences; The Royal Society of Chemistry: Cambridge, United Kingdom, 2016; pp. 23-46.

77. Günther, G.; Berríos, E.; Pizarro, N.; Valdés, K.; Montero, G.; Arriagada, F.; Morales, J. Flavonoids in Microheterogeneous Media, Relationship between Their Relative Location and Their Reactivity towards Singlet Oxygen. PLoS ONE 2015, 10, e0129749. [CrossRef] [PubMed]

78. Morales, J.; Günther, G.; Zanocco, A.L.; Lemp, E. Singlet Oxygen Reactions with Flavonoids. A TheoreticalExperimental Study. PLoS ONE 2012, 7, e40548. [CrossRef] [PubMed]

79. Binks, B.P.; Rodrigues, J.A.; Frith, W.J. Synergistic Interaction in Emulsions Stabilized by a Mixture of Silica Nanoparticles and Cationic Surfactant. Langmuir 2007, 23, 3626-3636. [CrossRef] [PubMed]

80. Binks, B.P.; Whitby, C.P. Nanoparticle silica-stabilised oil-in-water emulsions: Improving emulsion stability. Colloids Surf. A Physicochem. Eng. Asp. 2005, 253, 105-115. [CrossRef]

81. Semenzato, A.; Baù, A.; Dall'Aglio, C.; Nicolini, M.; Bettero, A.; Calliari, I. Stability of vitamin A palmitate in cosmetic emulsions: Influence of physical parameters. Int. J. Cosmet. Sci. 1994, 16, 139-147. [CrossRef]

82. Khanum, R.; Thevanayagam, H. Lipid peroxidation: Its effects on the formulation and use of pharmaceutical emulsions. Asian J. Pharm. Sci. 2017, 12, 401-411. [CrossRef]

83. Wispe, J.R.; Bell, E.F.; Roberts, R.J. Assessment of lipid peroxidation in newborn infants and rabbits by measurements of expired ethane and pentane: Influence of parenteral lipid infusion. Pediatr. Res. 1985, 19, 374-379. [CrossRef]

84. Pitkanen, O.; Hallman, M.; Andersson, S. Generation of Free Radicals in Lipid Emulsion Used in Parenteral Nutrition. Pediatr. Res. 1991, 29, 56-59. [CrossRef]

85. Siriwardhana, N.; Jeon, Y.-J. Antioxidative effect of cactus pear fruit (Opuntia ficus-indica) extract on lipid peroxidation inhibition in oils and emulsion model systems. Eur. Food Res. Technol. 2004, 219, 369-376. [CrossRef]

86. Patel, V.R.; Dumancas, G.G.; Viswanath, L.C.K.; Maples, R.; Subong, B.J.J. Castor Oil: Properties, Uses, and Optimization of Processing Parameters in Commercial Production. Lipid Insights 2016, 9, LPI.S40233. [CrossRef]

87. Vrolijk, M.F.; Opperhuizen, A.; Jansen, E.H.J.M.; Godschalk, R.W.; Van Schooten, F.J.; Bast, A.; Haenen, G.R.M.M. The shifting perception on antioxidants: The case of vitamin E and $\beta$-carotene. Redox Biol. 2015, 4, 272-278. [CrossRef] [PubMed]

88. Thiele, J.J.; Ekanayake-Mudiyanselage, S. Vitamin E in human skin: Organ-specific physiology and considerations for its use in dermatology. Mol. Asp. Med. 2007, 28, 646-667. [CrossRef] [PubMed]

89. Navarrete, M.; Rangel, C.; Corchado, J.C.; Espinosa-García, J. Trapping of the OH Radical by $\alpha$-Tocopherol: A Theoretical Study. J. Phys. Chem. A 2005, 109, 4777-4784. [CrossRef] [PubMed] 
90. Kaiser, S.; Di Mascio, P.; Murphy, M.E.; Sies, H. Physical and chemical scavenging of singlet molecular oxygen by tocopherols. Arch. Biochem. Biophys. 1990, 277, 101-108. [CrossRef]

91. Fukuzawa, K.; Matsuura, K.; Tokumura, A.; Suzuki, A.; Terao, J. Kinetics and Dynamics of Singlet Oxygen Scavenging by $\alpha$-Tocopherol in Phospholipid Model Membranes. Free Radic. Biol. Med. 1997, 22, 923-930. [CrossRef]

92. Aung, S.H.; Hao, Y.; Oo, T.Z.; Boschloo, G. Kinetic study of carminic acid and santalin natural dyes in dye-sensitized solar cells. J. Photochem. Photobiol. A Chem. 2016, 325, 1-8. [CrossRef]

93. Müller-Maatsch, J.; Gras, C. 18-The "Carmine Problem" and Potential Alternatives11Both authors contributed equally to this chapter. In Handbook on Natural Pigments in Food and Beverages; Carle, R., Schweiggert, R.M., Eds.; Woodhead Publishing: Duxford, UK, 2016; pp. 385-428. [CrossRef]

(C) 2020 by the authors. Licensee MDPI, Basel, Switzerland. This article is an open access article distributed under the terms and conditions of the Creative Commons Attribution (CC BY) license (http://creativecommons.org/licenses/by/4.0/). 